\title{
Letramento informacional em processos educativos digitais: padrão de comportamento informacional de docentes do curso de Pedagogia no uso de biblioteca digital
}

DOI: https://doi.org/10.26512/rici.v13.n1.2020.22879

Recebido/Recibido/Received: 2019-02-12

Aceitado/Aceptado/Accepted: 2019-10-01

Resumo: O objetivo deste estudo foi identificar o padrão de comportamento informacional dos docentes do curso de Pedagogia de uma instituição de educação superior privada do Distrito Federal no uso de sua biblioteca digital e como isso pode contribuir para suas práticas pedagógicas. Para tanto, foi utilizada técnica de grupo focal e os dados revelaram um padrão de comportamento informacional com contextos influenciados por estratégias institucionais, barreiras culturais e tecnológicas, mas com comportamentos específicos que qualificam o processo de ensino e aprendizagem por meio das atividades de busca científica e acadêmica, bem como pelas ações de prática docente e formação continuada.

Palavras-chave: comportamento informacional. pedagogia. biblioteca digital. biblioteca universitária. estudo de usuários.

Information literacy in digital educational processes: pattern of informational behavior of Pedagogy teachers in the use of digital library

Abstract: The objective of this study was to identify the informational behavior pattern of the teachers of the Pedagogy course of a Private Higher Education Institution of the Federal District in the use of their digital library and how this can contribute to their pedagogical practices. For this, a focus group technique was used, and the data revealed a pattern of informational behavior with contexts influenced by institutional strategies, cultural and technological barriers, but with specific behaviors that qualify the teaching and learning process through scientific research activities and academic practice, as well as for the actions of teaching practice and continuing education.

Keywords: informational behavior. Pedagogy. digital library. academic library. user studies.

Alfabetización informacional en procesos educativos digitales: patrón de comportamiento informativo de los docentes de pedagogía en el uso de la biblioteca digital

Resumen: El objetivo de este estudio fue identificar el patrón de información conductual de los maestros del curso de Pedagogía de una institución privada de educación superior del Distrito Federal en el uso de su biblioteca digital y cómo esto puede contribuir a sus prácticas pedagógicas. Para esto, se utilizó una técnica de grupo focal y los datos revelaron un patrón de comportamiento informativo con contextos influenciados por estrategias institucionales, barreras culturales y tecnológicas, pero con comportamientos específicos que califican el proceso de enseñanza y aprendizaje a través de las actividades de búsqueda científica y así como para las acciones de práctica docente y educación continua. 
Palabras clave: comportamiento informativo. pedagogía. biblioteca digital. biblioteca académica estudios de usuarios.

\section{Introdução}

Os conceitos de letramento informacional estão presentes em todas as etapas do processo de ensino e aprendizagem e reconhecê-los implica em uma mudança no próprio comportamento informacional de toda comunidade acadêmica, impactando nas práticas pedagógicas dos docentes. Entretanto, tais conceitos nem sempre são conhecidos, independentemente da área do saber, mesmo quando há o uso sistemático de espaços, recursos e tecnologias, como a biblioteca digital, que, notadamente, estruturam as atividades de letramento informacional.

Trata-se, portanto, do conceito de comportamento informacional como resultado do reconhecimento de alguma necessidade informacional, em que se avalia o que se tem e o que ainda falta em termos informacionais (WILSON, 1981), para atender diferentes demandas ou apoiar diferentes processos de tomada de decisão.

Considerando este contexto, e tendo como enfoque um Centro Universitário do Distrito Federal que reúne diferentes cursos de diferentes áreas do saber, questiona-se como se estrutura o comportamento informacional dos docentes do curso de Pedagogia no uso de sua biblioteca digital? Partindo deste questionamento, o objetivo deste estudo é identificar o padrão de comportamento informacional dos docentes do curso de Pedagogia de uma instituição de educação superior privada do Distrito Federal no uso de sua biblioteca digital e como isso pode contribuir para suas práticas pedagógicas. Especificamente, espera-se identificar os processos da biblioteca digital adotada pela IES, sistematizando-os em função dos seus fluxos informacionais; correlacionar os conceitos de letramento informacional aos processos da biblioteca digital; e verificar se as atividades de letramento informacional na biblioteca digital têm sido utilizadas pelos docentes em sua completude, como forma de aprimorar o processo de ensino e aprendizagem.

Conhecer os conceitos de letramento informacional, bem como reconhecê-los nos processos de biblioteca digital, pode aprimorar as experiências dos docentes em suas práticas acadêmicas e de pesquisa. Tal perspectiva indica que há espaços para discussão sobre o letramento informacional, neste caso o comportamento informacional, nas práticas pedagógicas e de investigação, independente da modalidade ou nível de ensino, visto a contínua busca pela competência informacional e aprendizagem significativa nos espaços acadêmico-escolares. 
O presente estudo é parte integrante do projeto "A Leitura e suas concepções teóricas, históricas e conceituais: perspectivas no campo do letramento informacional, da comunicação e comportamento informacional em diferentes instâncias educacionais formais e informais" aprovado sob o parecer de número 2.543.521.

\section{Letramento informacional e suas dimensões}

As relações dos bibliotecários com os processos de aprendizagem, como integrantes essenciais da comunidade acadêmica, permitem o estabelecimento de espaços e práticas para o desenvolvimento de habilidades e competências informacionais, impactando na aprendizagem e nas metas educacionais das pessoas (LAU, 2007). Isso envolve atributos de competência informacional, da capacidade de reconhecer as necessidades de informação, que habilita as pessoas para as atividades de exploração e interpretação da informação, bem como criação de novas ideias, com o desenvolvimento de novos conceitos. É nessa mesma perspectiva que está o conceito de letramento informacional, quando se considera o reconhecimento da necessidade de informação e, de forma significativa, realizam-se as atividades de busca, organização e uso da informação (GASQUE, 2010). Aponta-se, portanto, também para o conceito de competência e comportamento informacional. Com destaque à competência informacional, assim como Aguiar (2017) afirmou, parte-se da concepção da informação (ênfase na tecnologia da informação), concepção cognitiva (ênfase nos processos cognitivos) e concepção da inteligência (ênfase no aprendizado).

As atividades envolvidas pelo conceito de letramento informacional determinam habilidades, competências e comportamentos informacionais que direcionam as pessoas à reconhecerem sua necessidade de informação, gerarem novas informações e conhecimentos e socializarem o que foi apreendido. Essas habilidades infocomunicacionais têm sido apoiadas pelas novas tecnologias da informação e comunicação (BORGES, 2018), bem como delimitam o conceito de competência informacional, considerando que todas às dimensões do letramento informacional são atribuídas análise crítica e representatividade, e se favorece o compartilhamento de informações e, ainda, se considerada a perspectiva de Gasque (2012a), há todo o subsídio que o letramento informacional proporciona para os processos de tomada de decisão.

\subsection{Letramento informacional e as bibliotecas digitais}

Dizer que o letramento informacional pode estar presente em diferentes contextos, como o do uso da biblioteca digital, é o reconhecimento que nos processos metodológicos, ou seja nas atividades de pesquisa, estão incluídos os fundamentos do letramento informacional. 
Nesta perspectiva, o letramento informacional passa a representar o processo de aprendizagem que sobressai ao aspecto textual e aponta para o aprimoramento da busca e do uso da informação (GASQUE, 2012a).

Trabalhar os processos de busca e uso da informação em bibliotecas digitais, considerando o reconhecimento da necessidade de informação, busca e uso, vai ao encontro das estratégias colocadas por Gasque (2012b) para a atenção, reflexão e parecer dentro dos princípios do letramento informacional, trabalhado conteúdos em função da aprendizagem e do entendimento de diversos fenômenos.

O uso de bibliotecas digitais pode ensinar o letramento informacional porque, constituindo as atividades de pesquisa, estão vários conceitos do letramento informacional, desde o reconhecimento da necessidade de informação, busca (por meio de fontes específicas de informação), uso e compartilhamento da informação, podendo, inclusive, desenvolver mecanismos de aprendizagem autônoma, participativa e colaborativa, de modo a promover a construção de conhecimento, como bem colocou Campello (2003), corroborado por Peres (2011).

Se os fundamentos do letramento informacional forem entendidos, pode haver um aprimoramento das atividades de pesquisa, desenvolvendo competência informacional nos pesquisadores, ampliando a produtividade e a produção científica. Para tanto, os programas de letramento informacional devem ser ampliados e planejados pelas instituições, considerando a realidade, necessidades e contextos aos quais estão inseridas, como Gasque (2012a) colocou ao tratar dos desafios decorrentes dos processos de organização curricular. A partir daí, pode-se reconhecer, inclusive, os conceitos de Ausubel (2003) sobre a aprendizagem significativa, como resultado de um processo de construção de conhecimento por meio da valorização dos conteúdos pesquisados e mediados, além das experiências e vivências de cada um. Essa ressignificação pode estimular a origem do que se chama de pensamento reflexivo, quando a redescoberta integra a curiosidade, a observação, o estudo, a prática, e a aplicação dos resultados de pesquisa. Aliás, como Gasque (2012b) afirmou, a reflexão pode ser entendida, no sentido lato, como esforço do pensamento particular e, no estrito, como concentração do pensamento sobre si mesmo como objeto dele próprio, constituindo-se em um sentido interior, mas intelectual e deliberado.

\section{Comportamento informacional}

O modelo de comportamento informacional e comportamento de busca de informação adotado neste trabalho é o modelo revisado de Wilson (1999). Esta proposta correlaciona as definições de comportamento informacional sob a égide de quatro 
perspectivas: (i) o próprio comportamento informacional; (ii) o comportamento de busca (seeking) de informações; (iii) comportamento de pesquisa (searching) de informações; e (iv) comportamento de uso da informação (WILSON, 2000) (Quadro 1).

Quadro 1: Definições para comportamento informacional por Wilson (2000)

\begin{tabular}{ll}
\hline Comportamento informacional & $\begin{array}{l}\text { Envolvimento com relação aos tipos de fonte e canais de } \\
\text { informação, sob perspectivas ativa (interação face a } \\
\text { face) e passiva (sem interação entre emissor e receptor). }\end{array}$ \\
\hline Comportamento de busca de informações & $\begin{array}{l}\text { Busca intencional por informações como consequência } \\
\text { de uma necessidade informacional específica. }\end{array}$ \\
\hline Comportamento de pesquisa de & $\begin{array}{l}\text { Uso de argumentos e operadores para refinar o processo } \\
\text { de busca, com adoção de estratégias de pesquisa e } \\
\text { informações }\end{array}$ \\
\hline \multirow{2}{*}{ critérios de seleção. }
\end{tabular}

Fonte: Wilson (2000). Adaptado pelo autor.

As definições para comportamento informacional, conforme proposto por Wilson (2000), apresenta elementos do seu modelo de comportamento informacional, versando desde a necessidade da informação até a satisfação da informação, considerando que esta necessidade foi atendida por meio das atividades de busca, organização, uso e compartilhamento da informação (Figura 1).

Figura 1: Modelo de comportamento informacional

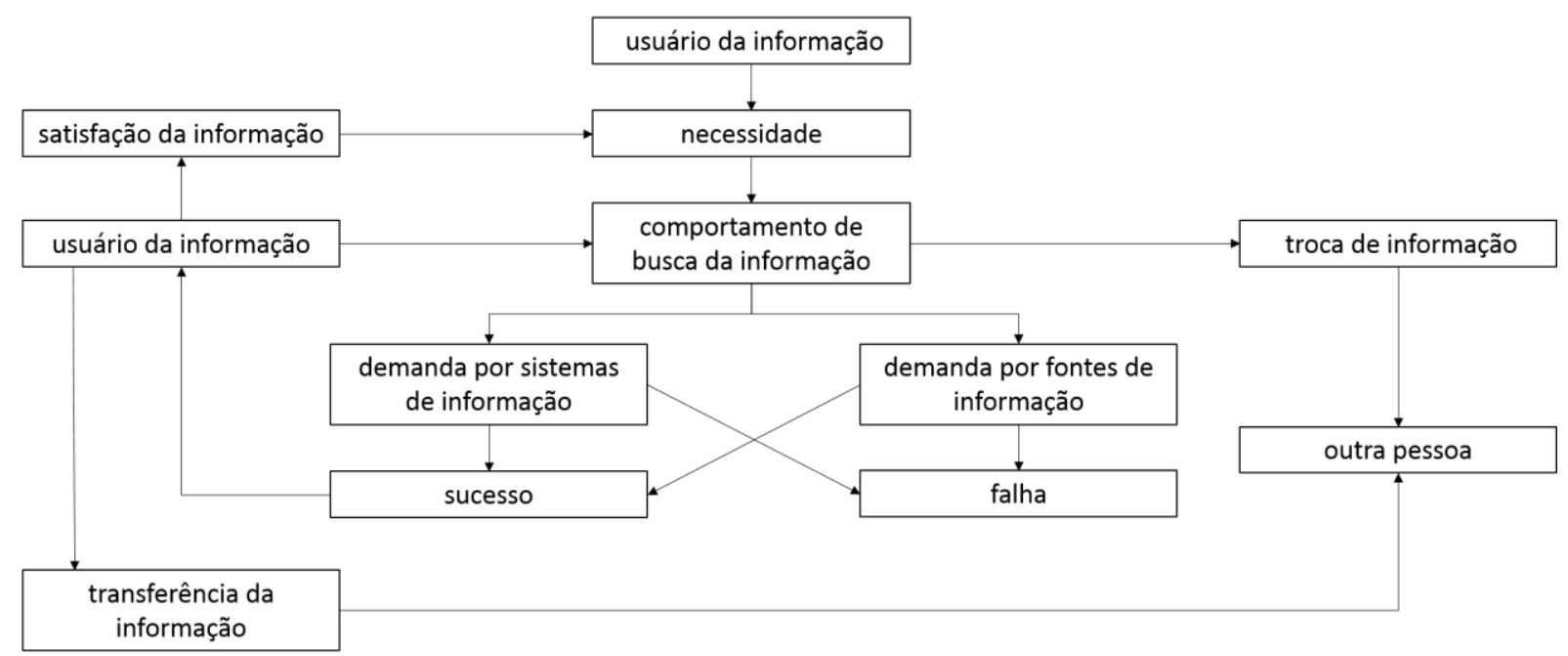

Fonte: Wilson (1999, p. 251, tradução nossa).

De forma sumária, a Figura 1 mostra um modelo que parte do usuário da informação que, a partir de uma necessidade informacional - que pode ser nova ou para complementar uma informação não satisfeita. A necessidade informacional implica o comportamento pela busca de informação, por meio de fontes ou sistemas de informação. Considerando o modelo, 
ao término do processo, a necessidade informacional pode ser satisfeita, ou não, dependendo do tipo de informação recuperada e a aderência disto às expectativas do usuário da informação.

Levando em conta o contexto do usuário da informação, bem como as diferentes demandas sociais que influenciam nas suas necessidades informacionais, Wilson (1999) sugere barreiras que podem impedir a busca por informações (Figura 2).

Figura 2: Modelo de comportamento de busca de informação
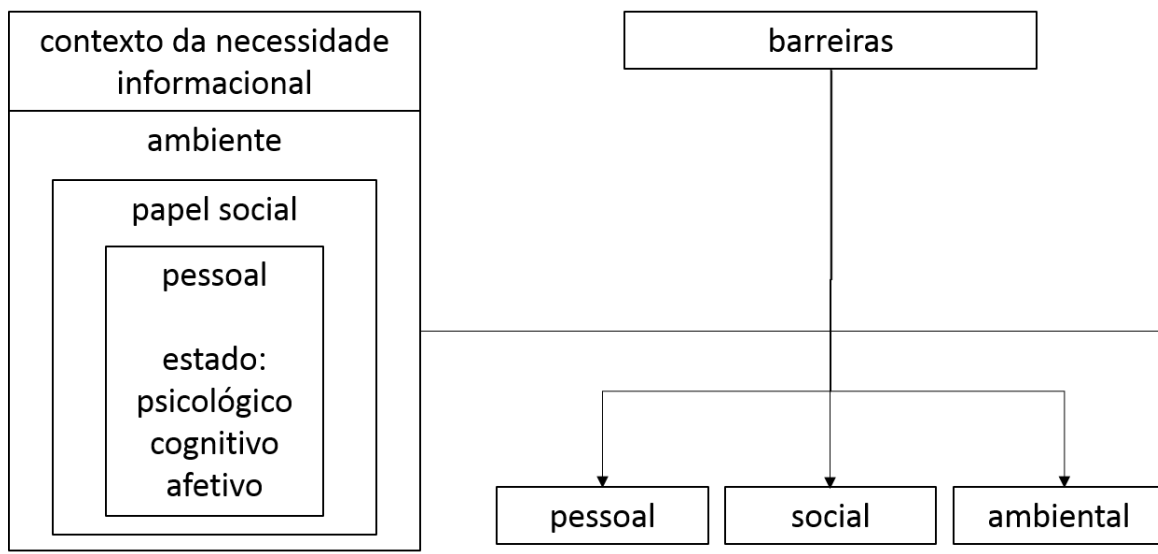

comportamento de busca de informação

Fonte: Wilson (1999, p. 252, tradução nossa).

Ao contrário do modelo apresentado na Figura 1, o modelo de comportamento de busca de informação que considera o contexto da necessidade informacional traz elementos implícitos e de mensuração subjetiva. A Figura 3, por sua vez, traz a revisão do modelo de comportamento informacional (WILSON, 1999).

Figura 3: Modelo revisado de comportamento informacional

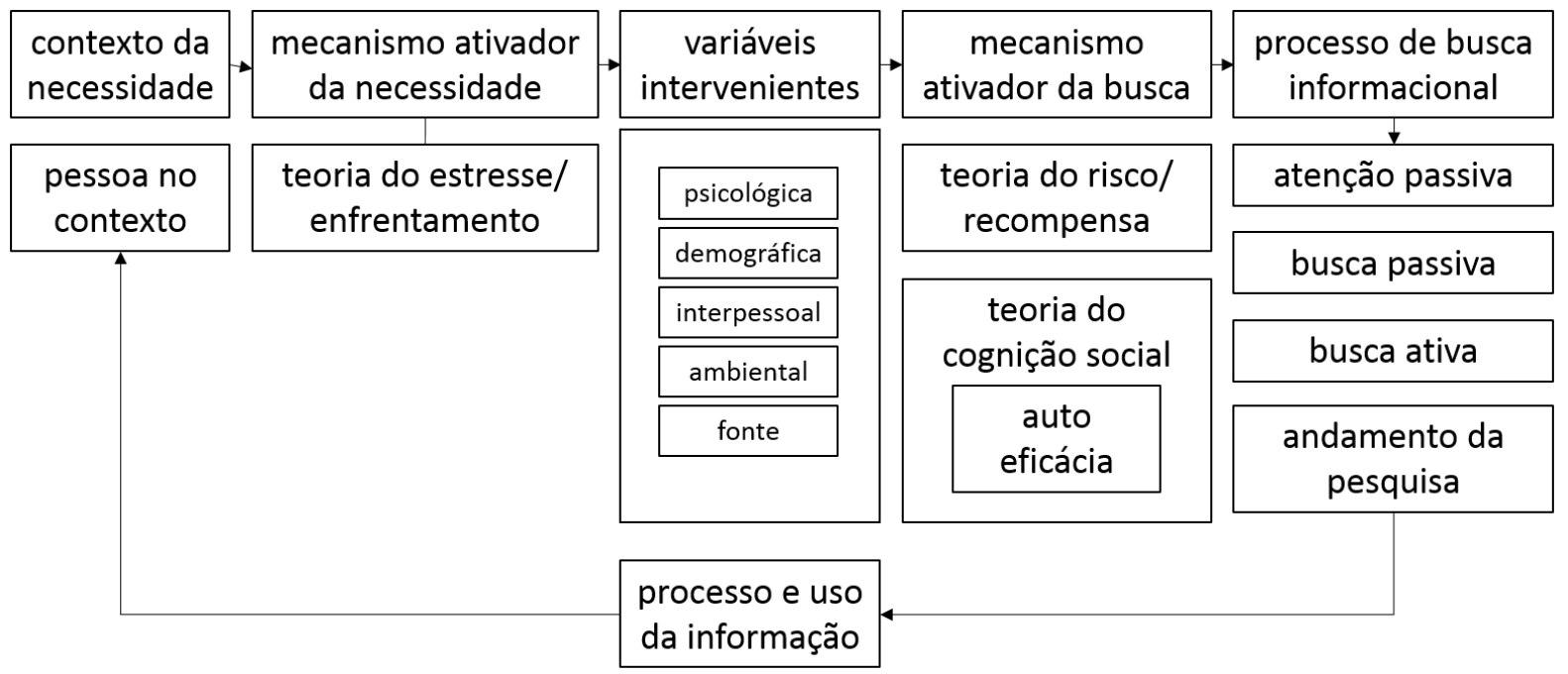

Fonte: Wilson (1999). 
O modelo revisado de comportamento informacional (Figura 3) apresenta macro comportamentos e categorias que incluem outros modelos teóricos, compreendendo estruturas mais sofisticadas para a busca/pesquisa informacional. A estrutura básica continua tendo como foco a necessidade informacional e as barreiras passam a ser consideradas como variáveis intervenientes (SILVA; MOREIRA; SILVA, 2014).

\section{Metodologia}

Este estudo pode ser classificado como de natureza básica, visto que se volta para a construção de conhecimentos acerca de um determinado fenômeno e ainda pode ser marcado pela multidisciplinaridade (BULMER, 1978). No que se refere à abordagem metodológica, entende-se como de abordagem qualitativa, quando são consideradas características subjetivas e inferências humanas (CRESWELL, 2007). Quanto aos seus objetivos, trata-se de um estudo descritivo visto que busca descrever as apreensões de um grupo de docentes sobre os conceitos de letramento informacional em suas práticas em biblioteca digital. Segundo Raupp e Beuren (2006), as pesquisas descritivas preocupam-se me observar os fatos, registrá-los, analisá-los, classificá-los e interpretá-los sem interferência do pesquisador.

A Instituição de Educação Superior (IES),ambiente deste estudo, conta com uma população de cerca de 400 docentes, distribuídos em seus diferentes cursos de graduação. Esta IES tem cinco unidades de educação superior distribuídas em diferentes regiões do Distrito Federal. Das cinco unidades, quatro ofertam o curso de Pedagogia, que, ao todo, reúne 40 docentes, dos quais 33 participaram deste estudo.

No que se refere ao contexto de biblioteca estudado, além de suas bibliotecas físicas, a IES adotou o uso de plataforma virtual de biblioteca digital, que é um consórcio formado por quatro editoras de livros acadêmicos brasileiros, com estrutura para acesso a conteúdo técnico, acadêmico e científico por meio da Internet, reunindo mais de 8.000 títulos de diferentes áreas do saber.

Como padrão de comportamento informacional, foi utilizado o modelo de comportamento informacional de Wilson (1999). Considerou-se, para a determinação do padrão de comportamento informacional do grupo estudado, as seguintes categorias (WILSON, 1999): (i) contexto da necessidade; (ii) mecanismo ativador da necessidade; (iii) variáveis intervenientes; (iv) mecanismo ativador da busca; e (v) processo de busca informacional.

Sobre os procedimentos técnicos, este estudo é de levantamento com mediação de grupo focal com aplicação de perguntas abertas. Como técnica de coleta de dados foi utilizado 
o grupo focal que trata de grupos de discussão que dialogam sobre um tema em particular, ao receberem estímulos apropriados para o debate (BACKES et al., 2011).

Segundo Sudman e Braudburn (1982), perguntas abertas permitem a apresentação de opiniões mais completas, distinções mais completas e expressões sob a perspectiva dos respondentes. De forma sumária, as perguntas mediadas no grupo focal consistiam nas relações de preferência entre os diferentes tipos de biblioteca, nos determinantes para a escolha dos títulos na biblioteca virtual, nas políticas e formas de acesso e uso da biblioteca virtual e nos avanços e desafios sobre o uso da biblioteca virtual.

Foi realizada uma sessão de grupo focal, com duração de uma hora, seguindo roteiro estruturado que consiste na explanação do estudo e mediação das perguntas. Todo o grupo focal foi observado e registrado pelo pesquisador. Como categorias de análise, foram adotadas as mesmas categorias do modelo revisado de Wilson (1999) (Quadro 2).

Quadro 2: Categorias de análise

\begin{tabular}{ll}
\hline SEQ & CATEGORIA \\
\hline $\mathbf{0 1}$ & contexto da necessidade \\
\hline $\mathbf{0 2}$ & mecanismo ativador da necessidade \\
\hline $\mathbf{0 3}$ & variáveis intervenientes. \\
\hline $\mathbf{0 4}$ & mecanismo ativador da busca \\
\hline $\mathbf{0 5}$ & processo de busca informacional \\
\hline
\end{tabular}

Fonte: dados da pesquisa.

Para consecução da técnica de grupo focal, foi possível contar com o uso do laboratório de Psicologia, com separação translúcida, da mesma IES, o que permitiu maior interação, discussão e engajamento dos respondentes durante a aplicação da técnica. Houve apoio de uma professora, que também é psicóloga, para mediação das perguntas e registro das respostas.

Para a análise dos resultados, os dados gerados foram degravados, tabulados e, em seguida, foi utilizada a técnica de análise de conteúdo, conforme Bardin (2011), que estabelece três fases: (i) pré-análise; (ii) exploração; e (iii) tratamento (inferência e interpretação). Para realizar estas três etapas, no que se às análises qualitativas por meio da técnica de análise de conteúdo, foi utilizada a aplicação MAXQDA ${ }^{1}$ que permite importar, organizar, analisar,

\footnotetext{
${ }^{1}$ Disponível em: <https://www.maxqda.com/what-is-maxqda>. Acesso em: 06 maio 18.
} 
visualizar e publicar todas as formas de dados que podem ser coletados eletronicamente, incluindo entrevistas.

O procedimento de pré-análise contou, a partir dos dados degravados, com a leitura flutuante, de modo a perceber, em primeiro contato, as apreensões dos participantes do grupo focal. Optou-se, ainda, seguindo a técnica, pela exaustividade, ou seja, todas as respostas foram consideradas para as análises. Durante a pré-análise foi possível normalizar as respostas, mantendo somente aquelas representativas ao objetivo de pesquisa, respeitando a pertinência ao tema e a exclusividade aos objetos de análise.

Para exploração do material, os dados degravados foram editados e separados em categorias de análise, de modo a permitir o agrupamento dos dados a partir do esquema de categorias definido para este estudo.A partir dos dados gerados, a terceira fase permitiu a análise dos conteúdos por meio da inferência (variáveis inferidas), ou seja, verbalizações que induzem as respostas sobre as categorias de análise. Consecutivamente, as interpretações foram realizadas com base nas variáveis inferidas, fazendo referência ao marco teórico deste estudo.

\section{Apresentação e análise dos dados}

O Quadro 3 apresenta as verbalizações do grupo focal por semelhança, considerando os termos e expressões mais presentes em função das categorias de análise. Destaca-se que o fenômeno analisado é o comportamento informacional de docentes do curso de Pedagogia no contexto do uso da biblioteca digital de uma IES privada do Distrito Federal.

Quadro 3: Matricial de categoria de análise por semelhança

\begin{tabular}{ll}
\hline CATEGORIA & SEMELHANÇA \\
\hline & Em primeiro momento, prima-se pela utilização do \\
acervo da biblioteca física, visto que a IES tem cinco & bibliotecas em suas unidades de educação superior. \\
& Concorrente à esta preferência, há a ampla \\
& disponibilização e acesso aos livros digitalizados \\
& constantes na Internet. Releva-se que estes livros são \\
& digitalizados e não digitais, ou seja, não compõem a \\
Contexto da necessidade & biblioteca digital. Por outro lado, percebe-se a \\
& presença de títulos da biblioteca digital na composição \\
& do ementário do PCC do curso, sendo que, para cada \\
& unidade curricular, há um título digital na bibliografia \\
básica e dois na bibliografia complementar. Os & periódicos especializados não compõem a biblioteca \\
digital. Nos planos de ensino das unidades curriculares & precisa constar previsão e estímulo de acesso à \\
biblioteca digital, inclusive com cronograma de \\
treinamento. Há indicadores institucionais sobre acesso \\
e uso das bibliotecas físicas e digital.
\end{tabular}



programas institucionais: (i) programa de formação continuada e prática docente; e (ii) programas de metodologias ativas, participativas e inovadoras na educação superior. O primeiro programa contém elementos de letramento digital e promoção e uso de novas tecnologias da informação e comunicação para o processo de ensino e aprendizagem. O segundo programa reúne cinco metodologias ativas, das quais uma é específica para o curso de Pedagogia: Aprendizagem Baseada em Ensino e Pesquisa. Os instrumentos que estão no percurso desta metodologia apontam para o uso da biblioteca digital. Os indicadores institucionais sobre acesso e uso das bibliotecas físicas e virtual fazem parte do sistema de observação docente e desempenho docente, ambos subsidiam a avaliação docente realizada semestralmente pela coordenação de curso, direção acadêmica da educação superior e coordenação de recursos humanos. Existem oficinas pedagógicas para a formação em organização didático-pedagógica, dentre as quais há práticas que correlacionam as propostas pedagógicas e metodológicas, aos diferentes tipos de conteúdos e o uso das bibliotecas.

Mesmo com quatro editoras que compõem o consórcio da biblioteca digital, a maior parte dos títulos são da escola de ciências jurídicas e sociais. Há baixa quantidade de títulos da área de educação e de formação de professores. Apesar dos treinamentos

Variáveis intervenientes. oferecidos para uso da biblioteca digital, percebe-se que a plataforma poderia ser mais intuitiva, de modo a auxiliar na navegação e recuperação dos títulos. Por outro lado, os respondentes declaram não saber ou utilizam pouco os operadores lógicos em seus argumentos de busca. A sensação de folhear o livro físico é um fator que define a preferência por este tipo de livro.

O reconhecimento de que os recursos tecnológicos favorecem o processo de ensino e aprendizagem, sobretudo em uma sociedade de nativos digitais, amplia o uso da biblioteca digital. A biblioteca digital mecanismo ativador da busca pode ainda ser associada a outros recursos didáticos, os quais sejam tecnológicos ou não, incrementando a experiência dos estudantes em sua práxis pedagógica. Em 2013, a IES credenciou-se Centro Universitário e ampliou suas atividades de pesquisa, por meio de políticas institucionais.

Quando em situação de uso da biblioteca digital, o processo de busca informacional é realizado, em sua maioria, por meio de dispositivos móveis, como smartphones. As buscas tendem a ser intencionais e

Processo de busca informacional relacionadas à uma demanda pedagógica ou avaliativa. Há classificação de relevância dos títulos aos objetivos de estudo e conteúdo mediado. As informações recuperadas normalmente são compartilhadas entre os pares. 
Fonte: dados da pesquisa.

Considerando as categorias de análise, o contexto da necessidade de informação trouxe a perspectiva de que a necessidade é uma experiência subjetiva que tende a ser individual e em função de interesses particulares. Ou seja, a informação precisa fazer sentido ou corroborar para a explicação de diferentes fenômenos. Consoante aos objetivos deste estudo, para esta categoria, percebeu-se que a biblioteca digital não é de primeira escolha para os respondentes, visto que a utilização deste canal, normalmente, é resultado do insucesso nas buscas nos acervos físicos. Por outro lado, existem instrumentos institucionais que influenciam na decisão polo uso da biblioteca digital.

Sobre o que move os professores do curso de Pedagogia da IES estudada para satisfazer suas necessidades informacionais, ou seja, a categoria do mecanismo ativador da necessidade, existem programas específicos de formação continuada e prática docente e de metodologia ativa e participativa na educação superior. O engajamento dos docentes nestes programas resulta na utilização sistemática da biblioteca digital. Entretanto, para além dos aspectos formativos, existem questões pragmáticas que inibem um pouco a natureza voluntária para uso da biblioteca digital, que é o fato desse uso ser critério de avaliação do próprio docente, dentre o rol de critérios que definem a sua permanência ou não na instituição. Ainda assim, todas as práticas pedagógicas que envolvem o uso da biblioteca digital têm a participação de bibliotecário(a) para a construção da sequência didática e das estruturas metodológicas de pesquisa.

As apreensões consoantes às duas primeiras categorias estão conforme o modelo de comportamento informacional de Wilson (2000) que, assim como indicaram Gasque e Costa (2003), são definidas por aspectos psicológicos, afetivos ou cognitivos, correlacionando personalidade, papéis desempenhados e os vários contextos ambientais.

Existem variáveis que intervêm as necessidades de informação, bem como no uso da biblioteca digital, mas elas não são determinantes, visto que são adotadas ações para tornar a plataforma mais aderente às expectativas dos docentes, enquanto usuários, bem como formações para aprimorar os processos de busca e compartilhamento das informações. Assim, desenvolvem-se habilidades e competências informacionais, em contexto semelhante ao de Perrenoud (2000), quando afirma que a competência designa a capacidade de articular diferentes recursos cognitivos para entender diferentes situações.

Quando colocados os resultados do estudo em formato próximo ao modelo de comportamento informacional de Wilson (1999), há possibilidade de estruturar os temas recuperados no grupo focal, conforme apresenta a Figura 4, para a configuração de um 
possível padrão de comportamento informacional dos docentes do curso de Pedagogia no uso da biblioteca digital.

Figura 4: Comportamento informacional dos docentes do curso de Pedagogia no uso da biblioteca digital

\begin{tabular}{|c|c|c|c|}
\hline contexto da necessidade informacional & \multicolumn{2}{|c|}{ barreiras } & comportamento de busca de informação \\
\hline \multirow{4}{*}{$\begin{array}{l}\text { Programa de formação continuada e prática docente } \\
\text { Programa de metodologias ativas } \\
\text { Oficinas pedagógicas } \\
\text { Avaliação de desempenho } \\
\text { Tecnologias como recurso didático-metodológico } \\
\text { Novos instrumentos avaliativos de cursos superiores }\end{array}$} & & & \multirow{4}{*}{$\begin{array}{r}\text { Alinhamento pedagógico com biblioteca } \\
\text { Busca orientada à pesquisa científica } \\
\text { Busca orientada à pesquisa acadêmica } \\
\text { Formação continuada e letramento digital } \\
\text { Uso de recursos digitais e novas TIC } \\
\text { Compartilhamento de informações }\end{array}$} \\
\hline & & & \\
\hline & $\checkmark$ & & \\
\hline & cultura & $\begin{array}{c}\text { letramento } \\
\text { digital }\end{array}$ & \\
\hline
\end{tabular}

Fonte: dados da pesquisa.

O padrão de comportamento informacional dos docentes do curso de Pedagogia no uso da biblioteca digital mostra um contexto de necessidade informacional caraterizado e estimulado por programas específicos de formação pedagógico-acadêmica, aliados à métricas institucionais e de gestão. Nesse contexto, os docentes do curso de Pedagogia têm um comportamento de busca de informação acadêmica e científica planejado e intencional, com apoio de bibliotecário(a). As limitações digitais, bem como a superação às resistências culturais para o uso da biblioteca digital, são mitigadas pela formação continuada, literacia digital e o reconhecimento dos novos paradigmas sociais pautados na sociedade do conhecimento composta também por nativos digitais.

\section{Conclusões}

O objetivo deste estudo foi identificar o padrão de comportamento informacional dos docentes do curso de Pedagogia de uma Instituição de Educação Superior Privada do Distrito Federal no uso de sua biblioteca digital e como isso pode contribuir para suas práticas pedagógicas. Para alcançá-lo, foi adotada uma estratégia metodológica que contou com a mediação da técnica de grupo focal para 33 docentes do curso de Pedagogia.

Como categorias de análise do estudo, foram utilizadas as mesmas categorias do modelo de comportamento informacional do Wilson (2000) para busca de informações. Os dados revelaram que os docentes participantes deste estudo mantêm um padrão de comportamento informacional favorável ao uso da biblioteca digital. Por outro lado, é reconhecido que tal predisposição é impulsionada por estruturas institucionais torna o uso da biblioteca digital mandatário. Ainda assim, é perceptível o incremento qualitativo do processo 
de ensino e aprendizagem, sobretudo nas atividades de busca e uso da informação. Destaca-se que os acadêmicos têm novas experiências com o uso da biblioteca digital, para além daquelas já vivenciadas nas bibliotecas físicas.

Ainda existem questões culturais que são determinantes para a preferência pela biblioteca física, como a sensação do folhear as páginas do livro, mas o acervo digital tem assumido espaços nas sequências didático-pedagógicas dos docentes, visto o aporte formativo, tecnológico e administrativo que os suportam.

Sugere-se que a estrutura metodológica deste estudo seja aplicada para outros cursos, de outras áreas e instituições, de modo a perceber como se dá o comportamento informacional em biblioteca digital de professores em diferentes contextos e ambientes.

\section{Referências}

AGUIAR, N. C. de. A Contribuição Teórica de Kelley Cristine Gonçalves Dias Gasque para o Discurso da Competência Informacional no Brasil. Ciência da Informação em Revista, Maceió, v. 4, n. 1, p. 17-27, maio 2017.

AUSUBEL, D. P. Aquisição e retenção de conhecimentos: uma perspectiva cognitiva. Lisboa: Plátano, 2003.

BACKES, Dirce Stein et al. Grupo focal como técnica de coleta e análise de dados em pesquisas qualitativas. O mundo da saúde, v. 35, n. 4, p. 438-42, 2011.

BARDIN, L. Análise de conteúdo. São Paulo: Edições 70, 2011

BORGES, J. Competências infocomunicacionais: estrutura conceitual e indicadores de avaliação. Informação e Sociedade, v. 28, n. 1, p. 123-140, 2018.

BULMER, M. Social policy research. London: Macmillan, 1978.

CAMPELLO, B. O movimento da competência informacional: uma perspectiva para o letramento informacional. Ciência da Informação, Brasília, v. 2, n. 3, p. 28-37, set./dez. 2003.

CAMPELLO, B. Letramento informacional no Brasil: práticas educativas de bibliotecários em escolas de ensino básico. 2009. 208 f. Tese (Doutorado em Ciência da Informação) - Escola de Ciência da Informação, Universidade Federal de Minas Gerais, Belo Horizonte, 2009.

CRESWELL, John W.; CLARK, Vicki L. Plano. Designing and conducting mixed methods research. 2007.

GASQUE, K. C. G. D. Letramento informacional: pesquisa, reflexão e aprendizagem. Brasília: $\mathrm{FCl} / \mathrm{UNB}, 2012.178 p$. 
GASQUE, K. C. G. D. Delineamento do conceito de letramento e termos relacionados. In: GASQUE, K. C. G. D. Letramento informacional: pesquisa, reflexão e aprendizagem. Brasília: Faculdade de Ciência da Informação / Universidade de Brasília, 2012, p. 28-39.

GASQUE, K. C. G. D. Arcabouço conceitual do letramento informacional. Ciência da Informação, Brasília, DF, v. 39, n. 3, p. 83-92, set./dez. 2010.

GASQUE, K. C. G. D.; COSTA, S. M. de S. Comportamento dos professores da educação básica na busca da informação para formação continuada. Ciência da Informação, v.32, n.3, p.54-61, 2003.

LAU, J. Diretrizes sobre desenvolvimento de habilidades de informação para a aprendizagem permanente. Boca del Rio: [s.n], 2007.

PERES, Mônica Regina. Competência informacional: educação e sociedade. Revista IberoAmericana de Ciência da Informação, v. 4, n. 1, p. 22-34, 2011.

PERRENOUD, P. Dez novas competências para ensinar: convite à viagem. Porto Alegre: Artmed, 2000.

RAUPP, Fabiano Maury; BEUREN, Ilse Maria. Metodologia da Pesquisa Aplicável às Ciências. São Paulo: Atlas, 2006.

SILVA, C. M. M. da; MOREIRA, J. R.; SILVA, J. R. de F. Comportamento informacional versus comunicação: aplicação de modelos em contextos multidisciplinares. Biblos: Revista de Bibliotecología y Ciencias de la Información, n. 57, 2014.

SUDMAN, S.; BRADUM, N. M. Asking questions. San Francisco: Jossey-Bass, 1982.

WILSON, T. D. On user studies and information need's. Journal of Documentation, London, v. 37, n. 1, p. 3-15, 1981.

WILSON, T. D. Information behaviour: an interdisciplinary perspective. Information Processing and Management, v. 33, n. 4, p. 551-572, 1997.

WILSON, T. D. Models in information behaviour research. Journal of documentation, v. 55, n. 3, p. 249-270, 1999.

WILSON, T. D. Human information behaviour. Information Science, v. 3, n. 2, p. 49-54, 2000. 